https://doi.org/10.11646/zootaxa.4504.3.4

http://zoobank.org/urn:lsid:zoobank.org:pub:5D91D1A9-413B-4704-A78E-4402FC449943

\title{
Revision of the family Carabodidae (Acari: Oribatida) XVI. Synkrotima tsalakpmenoi sp. nov. from Zimbabwe and Kenya, and Congocepheus thailandae sp. nov. from Thailand, including a complementary study of Cavaecarabodes hauseri (Mahunka 1989)
}

\author{
NESTOR FERNANDEZ ${ }^{1,2,5}$, PIETER THERON ${ }^{2}$, SERGIO LEIVA ${ }^{3} \&$ ANINE JORDAAN $^{4}$ \\ ${ }^{l}$ National Council of Scientific and Technological Research, Argentina (CONICET). Evolutive Genetic Laboratory FCEQyN , Mis- \\ iones National University. Felix de Azara 1585, 6(3300) Posadas Misiones Argentina. E-mail: nestorfernand51@yahoo.fr \\ ${ }^{2}$ Research Unit for Environmental Sciences and Development, North-West University, Potchefstroom Campus, 2520, South Africa. \\ E-mail: pieter.theron@nwu.ac.za \\ ${ }^{3}$ National Institute Agricultural Technology (INTA). Experimental Rural Agency, Aimogasta. 5910. La Rioja. Argentina. \\ E-mail: sergiodanteleiva@yahoo.ar. \\ ${ }^{4}$ Laboratory for Electron Microscopy, North-West University, Potchefstroom Campus, 2520 (South Africa).anine.jordaan@nwu.ac.za \\ ${ }^{5}$ Corresponding author.E-mail: nestorfernand51@yahoo.fr
}

\begin{abstract}
Synkrotima tsalakpmenoi sp. nov. is described from material collected in Zimbabwe and Kenya. This species presents the following characteristics: notogastral integument formed by longitudinally aligned cuticular cords; thick, lanceolate notogastral setae; and genital neotrichy. Synkrotima tsalakpmenoi sp. nov. is compared to S. zimbabwae. Congocepheus thailandae sp. nov. is the first species of this genus described from Thailand, with the following present: large finger-like notogastral projection; notogastral setae $c_{1}, c_{2}, d a, d m, d p, l a, l m, l p, h_{1}, h_{2}$ situated on promontories; setae $c_{1}, c_{2}$ located adjacent and parallel.

A complementary study of Cavaecarabodes hauseri, making use of Scanning Electron Microscopy (SEM), allows for clarification of particularities regarding complex setae as well as some aspects of the integument, and provides a more detailed diagnosis.
\end{abstract}

Key words: systematics, Africa, Asia, optical microscopy, scanning electron microscopy, comparison

\section{Introduction}

The first species described and named in this paper, Synkrotima tsalakpmenoi sp. nov. is the second species assigned to this genus. Despite prolonged conservation of the material we were able to produce acceptable SEM images of material sampled in Zimbabwe (1945) as well as in Kenya (1977).

The second species described in this paper is Congocepheus thailandae sp. nov., the first known species of the genus from Thailand. A comparison with Co. orientalis Mahunka 1987 is also supplied.

A complementary description of Cavaecarabodes hauseri (Mahunka 1989) (Fernandez et al. 2013a; 2014) is provided. This species is very complex, and SEM images provide further clarity on aspects such as cuticular microsculpture and setae, which were previously only studied with optical microscopy. The type material Mahunka (1989) deposited in the Muséum d'Histoire Naturelles, Genève (MHNG), was collected in Sumatra while the material used in this study was collected in Vietnam.

\section{Materials and methods}

Specimens studied by means of light microscopy were macerated in lactic acid, and observed in the same medium 
using the open-mount technique (cavity slide and cover slip) as described by Grandjean (1958) and Krantz \& Walter (2009). Drawings were made using a Zeiss GFL (West Germany) compound microscope equipped with a drawing tube.

The techniques used in optical microscopy and SEM investigations of the examined specimens follow those proposed by Fernandez et al. (2016), and equipment used is the same as for previous studies (see Fernandez et al 2016).

Measurements taken: total length (tip of rostrum to posterior edge of notogaster); width (widest part of notogaster); all body measurements in micrometers $(\mu \mathrm{m})$.

Leg chaetotaxy studies making use of standard, polarized and phase contrast microscopes are provisional, due to the fact that only adult specimens were available for study. Setal formulae of the legs include the number of solenidia (in parentheses); tarsal setal formulae include the famulus $(\varepsilon)$.

Morphological terminology. Morphological terms and abbreviations used are those developed by F. Grandjean (1928-1974) (cf. Travé \& Vachon, 1975; Norton \& Behan-Pelletier 2009; Fernandez et al. 2013a, b; 2014). For setal types and ornamentation of cuticular surfaces, Evans (1992) was used. We add the following term: semi-circular groove (c.g).

Institutions: Muséum d'Histoire Naturelles, Genève (MHNG).

\section{New taxa descriptions}

\section{Synkrotima tsalakpmenoi sp. nov.}

(Figures 1-41)

Etymology. The specific epithet "tsalakpmenoi" is derived from $(\operatorname{t\sigma } \alpha \lambda \alpha \kappa \omega \mu \varepsilon ́ v o$ Greek=, wrinkled = English) due to characteristics of the notogastral cuticular surface.

Material examined. Holotype. Female "Zimbabwe, Mutare II/1945. Leg. R. Mussard"; material deposited in the Collection of the Natural History Museum of Geneva (MHNG), Switzerland; preserved in 46\% ethanol. Paratypes. Two adult females from different localities, namely "Zimbabwe, Mutare II/1945. Leg. R. Mussard" and "Kenya. Embu distr. Kirimiri Forest, Ouest de Runyenje, alt. 1586 m; tamisage dans la forêt 13 /X/1977. Leg. V. Mahnert \& J.L. Perret"; material deposited in the Collection of the MHNG; preserved in 46\% ethanol. Material studied by means of SEM: three female specimens, not deposited.

Diagnosis (adult female). Integument. Notogaster: longitudinally aligned cuticular chords forming rugose integument.

Setation. Lanceolate, thick, medial longitudinal zone elevated, with small dentitions, triangular in crosssection: notogastral; adanal setae. Lanceolate, with small dentitions, barbate: le. Lanceolate, more or less flat, with elevated medial longitudinal zone: rostral, lamellar setae.

Simple, smooth: anal; simple, with small barbs; epimeral setae $4 a, 4 b$ particular shape: $4 a$ thin, elongate, $4 b$ triangular, curved. Simple, sharply tipped: subcapitular setae; flabellate: genital, aggenital setae.

Prodorsum. Complex elevated interlamellar process flat, slightly elevated; polyhedral lateral processes with parallel oblique grooves, one on either side; T-shaped anterior projection. Lamellae resembling elevated ribbon.

Notogaster. Humeral apophysis ovoid, anterior end barely overlapping posterior bothridial zone.

Lateral zone. Deep supratutorial depression; small anterior supratutorial depression. Depressions above and behind acetabulum IV; longitudinal oblique depression posterior to acetabulum IV.

Ventral region. Discidium with triangular sharp tip. Genital plate smaller than anal plate. Shallow depression surrounding elevated zone bearing genital plate; anterior genital furrow present; genital neotrichy 6 to 11 pairs of setae, symmetric or asymmetric distribution.

Large, deep furrow surrounding anterior and medial zones of anal opening, not extending to posterior zone. Adanal setae $a d_{3}$ and $a d_{2}$ situated on lateral furrow surrounding anal opening; $a d_{1}$, outside the lateral furrow.

Description. Measurements. Female, length 827 (658-958) (ten animals measured), width 347 (298-438) (ten animals measured).

Shape. Prodorsum polyhedral, notogaster elongate ovoid (Figures 1, 2, 10)

Colour. Specimens without cerotegument: brown to dark brown, slightly shiny when observed in reflected light. 


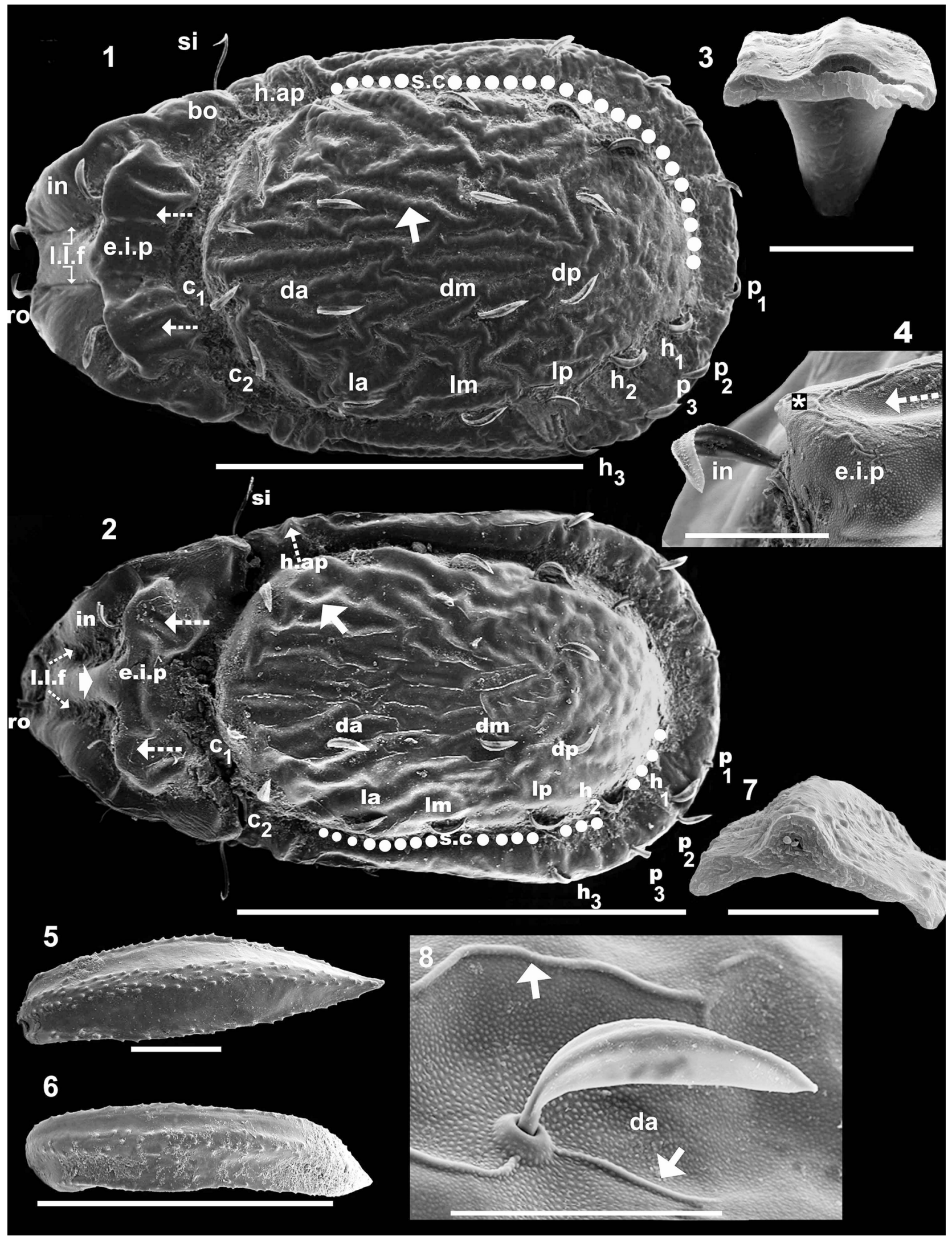

FIGURES 1-8. Synkrotima tsalakpmenoi sp. nov. Adult female, SEM. 1. dorsal view, female (Zimbabwe); 2. dorsal view, female (Kenya); 3. frontal view, broken notogastral da seta; 4. elevated interlamellar protuberance and interlamellar seta; $\mathbf{5}$. notogastral $d a$ seta; 6. notogastral $c_{2}$ seta; 7. frontal view, broken notogastral $c_{2}$ seta; 8. notogastral seta $d a$, and notogastral elevated cuticular ridges. Abbreviations: see Material and Methods. Scale bars: $1=590 \mu \mathrm{m} ; \mathbf{2}=590 \mu \mathrm{m} ; \mathbf{3}=5 \mu \mathrm{m} ; \mathbf{4}=100 \mu \mathrm{m}$; $\mathbf{5}=10 \mu \mathrm{m} ; \mathbf{6}=59 \mu \mathrm{m} ; \mathbf{7}=5 \mu \mathrm{m} ; \mathbf{8}=40 \mu \mathrm{m}$. 


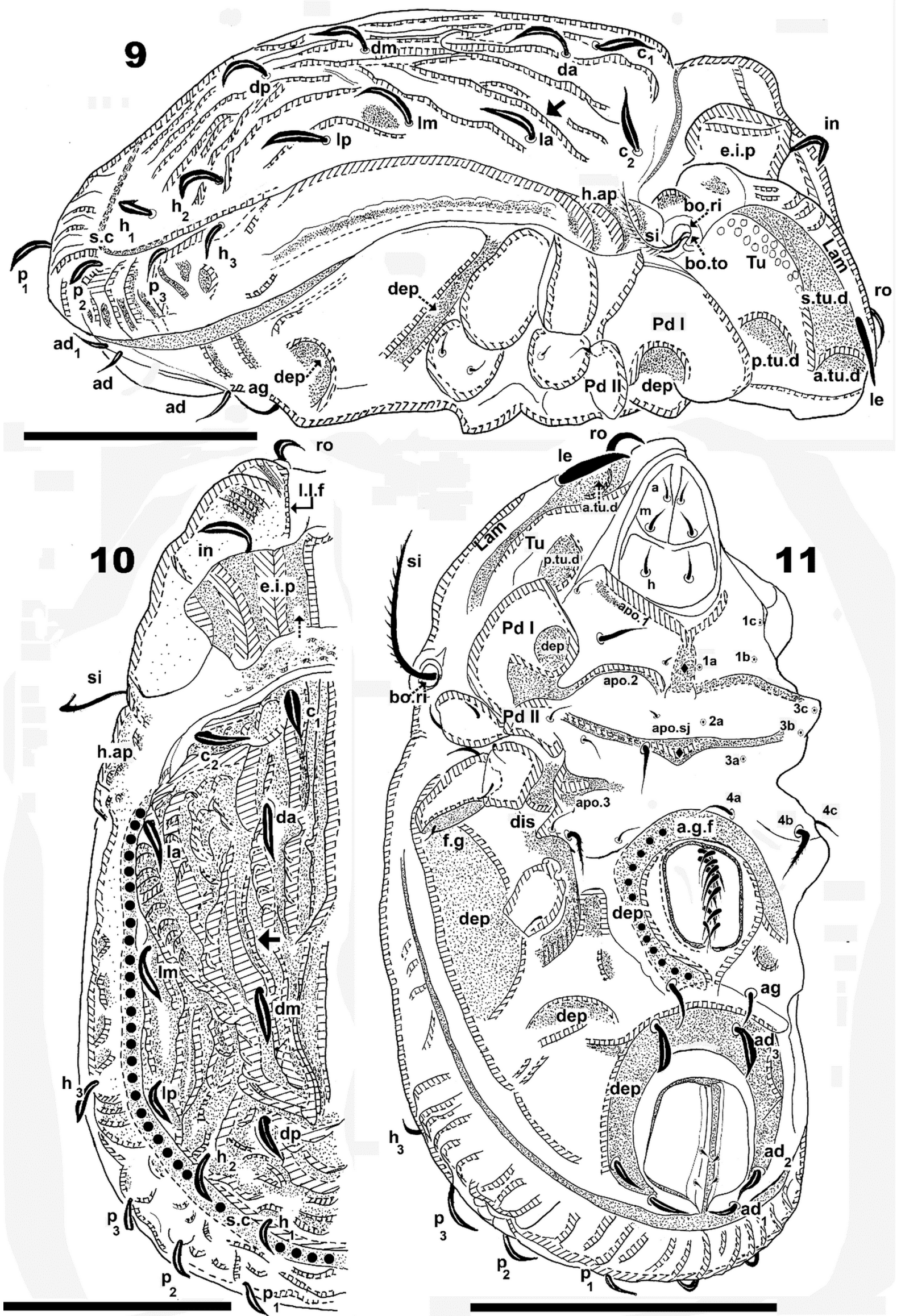

FIGURES 9-11. Synkrotima tsalakpmenoi sp. nov. Adult female, optical microscopy. 9. lateral view; 10. dorsal view; 11. ventral view. Scale bars: 9=200 $\mu \mathrm{m} ; \mathbf{1 0}=250 \mu \mathrm{m} ; \mathbf{1 1}=320 \mu \mathrm{m}$. 


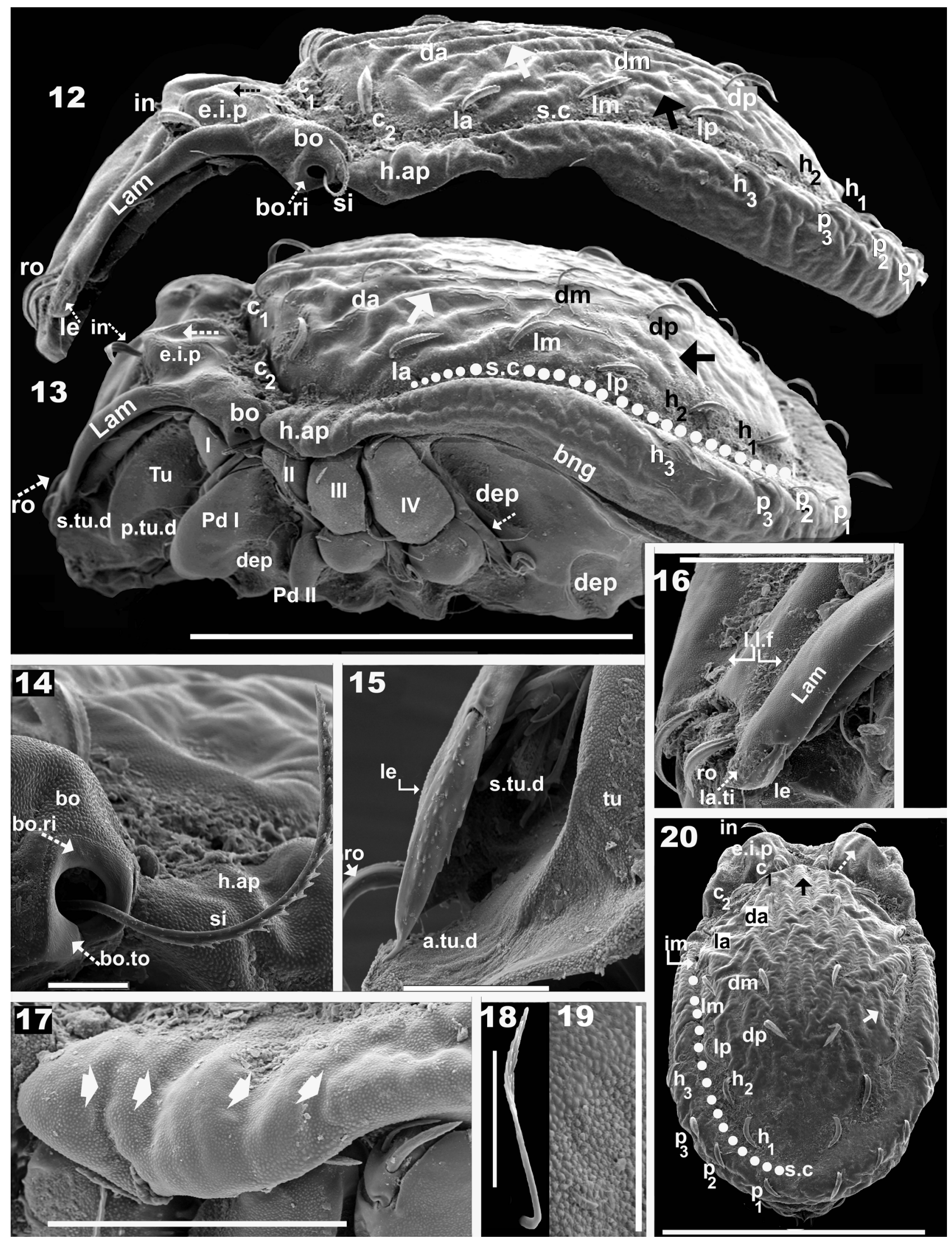

FIGURES 12-20. Synkrotima tsalakpmenoi sp. nov. Adult female, SEM. 12. partial lateral view (Zimbabwe); 13. lateral view (Kenya); 14. bothridium and sensillus; 15. lamellar setae; 16. prodorsal anterolateral zone; 17. humeral apophysis, lateral view; 18. epimeral seta $3 a ; \mathbf{1 9}$. bothridial cuticular microsculpture; 20. dorsoposterior view. Scale bars: 12; 13=590 $\mu \mathrm{m} ; \mathbf{1 4}=20 \mu \mathrm{m}$; 15 $=50 \mu \mathrm{m} ; \mathbf{1 6}=100 \mu \mathrm{m} ; \mathbf{1 7}=100 \mu \mathrm{m} ; \mathbf{1 8}=20 \mu \mathrm{m} ; \mathbf{1 9}=15 \mu \mathrm{m} ; \mathbf{2 0}=590 \mu \mathrm{m}$. 


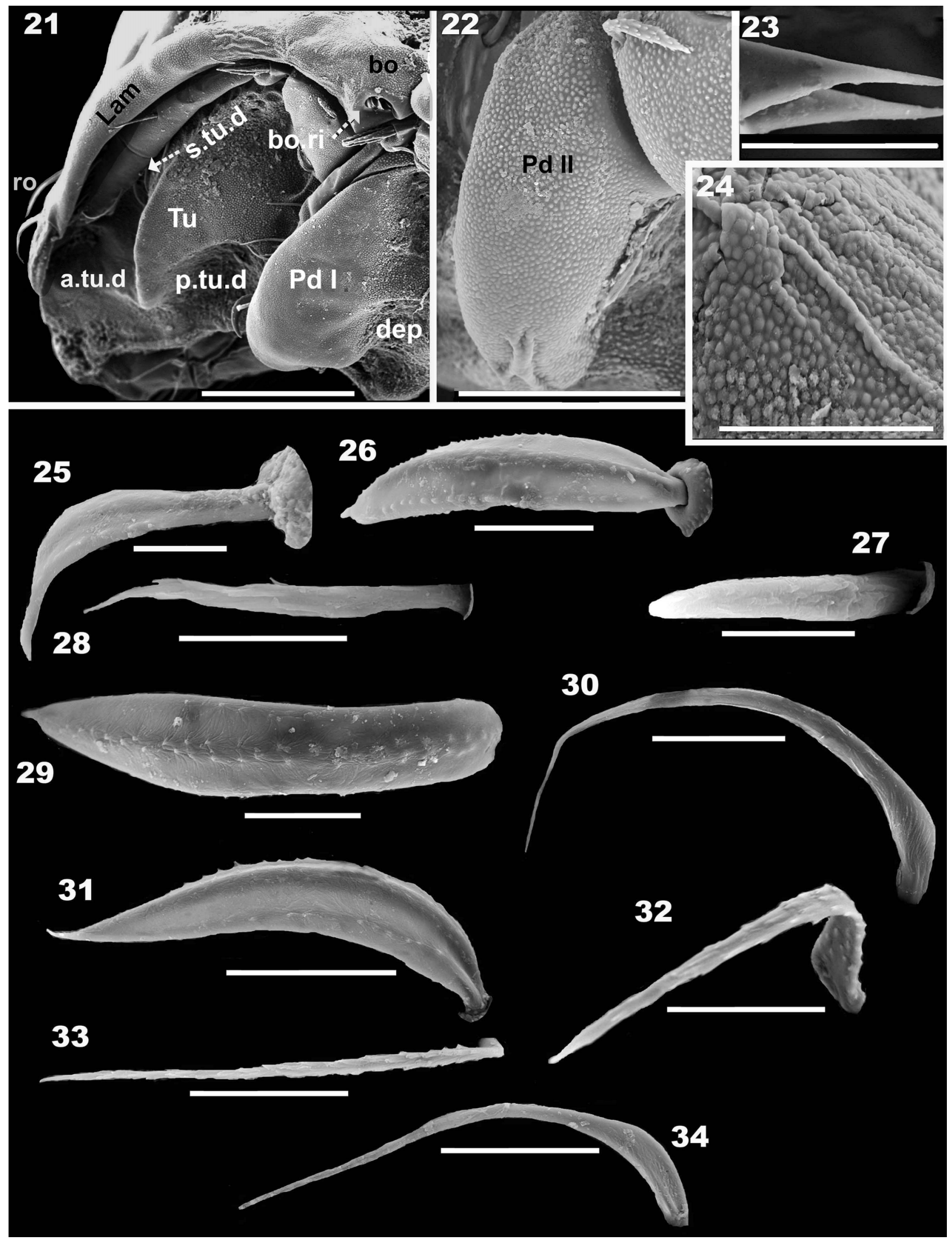

FIGURES 21-34. Synkrotima tsalakpmenoi sp. nov. Adult female, SEM. 21. anterolateral view; 22. pedotectum II, lateral view; 23. anal plate, sharp tip; 24. cerotegumental layer, bothridial zone; 25. rostral seta; 26. notogastral seta $p_{3} ; 27$. anal seta, $a n_{2} ; 28$. subcapitular seta $h$; 29. adanal seta, $a d_{2}$, dorsal view; 30. aggenital seta; 31. adanal seta $a d_{3}$, lateral view; 32. epimeral seta, $4 b$; 33. epimeral seta $4 a$; 34. genital seta. Scale bars: $\mathbf{2 1}=100 \mu \mathrm{m} ; \mathbf{2 2}=59 \mu \mathrm{m} ; \mathbf{2 3}=10 \mu \mathrm{m} ; \mathbf{2 4}=30 \mu \mathrm{m} ; \mathbf{2 5}=10 \mu \mathrm{m} ; \mathbf{2 6}=15$ $\mu \mathrm{m} ; \mathbf{2 7}=\mathbf{5} \mu \mathrm{m} ; \mathbf{2 8}=10 \mu \mathrm{m} ; \mathbf{2 9}=10 \mu \mathrm{m} ; \mathbf{3 0}=20 \mu \mathrm{m} ; \mathbf{3 1}=10 \mu \mathrm{m} ; \mathbf{3 2}=20 \mu \mathrm{m} ; \mathbf{3 3}=20 \mu \mathrm{m} ; \mathbf{3 4}=25 \mu \mathrm{m}$. 

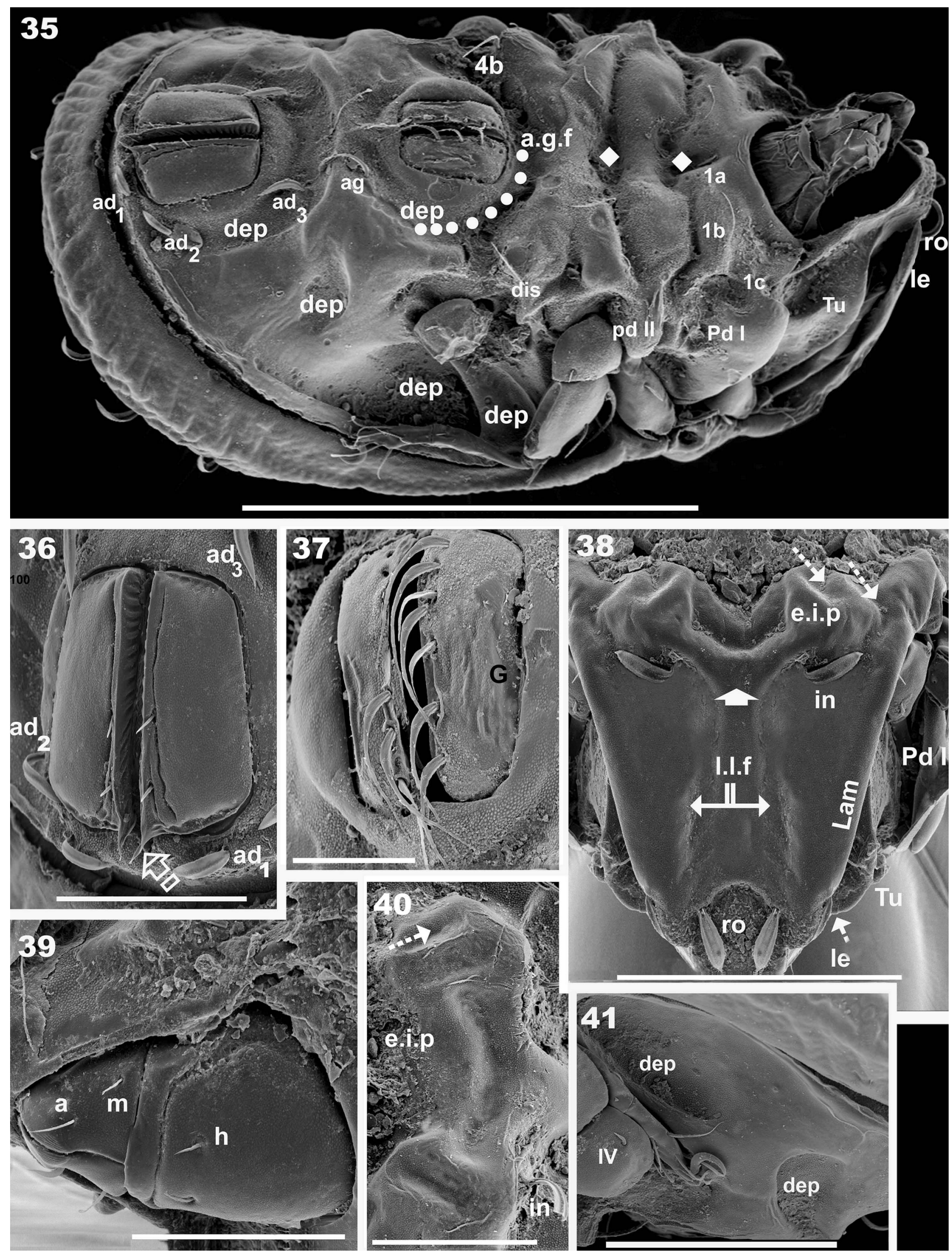

FIGURES 35-41. Synkrotima tsalakpmenoi sp. nov. Adult female, SEM. 35. ventrolateral view; 36. anal plates; 37. genital plates; 38. prodorsum frontal view; 39. subcapitulum, lateral view; 40. elevated interlamellar process, dorsal view; 41. posterolateral view. Scale bars: 35=590 $\mu \mathrm{m} ; \mathbf{3 6}=100 \mu \mathrm{m} ; \mathbf{3 7}=59 \mu \mathrm{m} ; \mathbf{3 8}=200 \mu \mathrm{m} ; \mathbf{3 9}=100 \mu \mathrm{m} ; \mathbf{4 0}=100 \mu \mathrm{m} ; \mathbf{4 1}=180 \mu \mathrm{m}$. 
Cerotegument. Present: thin granular layer, following cuticular microsculpture; thickness 0.5 to 0.9 (Figures $12,15,24)$.

Integument. Pusticulate: notogaster (Figure 8); bothridial zone (Figures 14, 19); pedotectum II (Figure 22). Rugose, formed by cuticular cords, principally aligned longitudinally (Figures 1, 2, 8, 12, 13, 20 indicated by i): notogaster (Figures 1, 8, 12,13,20), in some specimens elevations on central notogastral zone more accentuated (Figures 1, 8, 12, 20), in others less (Figures 2, 13); prodorsal zone of elevated interlamellar process (e.i.p) (Figure 4); Smooth: prodorsum (1, 2, 12, 13, 16, 21, 38, 40); humeral apophysis (h.ap) (Figure 17); ventral region (epimeral zone, ano-adanal zone) (Figure 35); anal plate (Figure 36); genital plate (Figure 37); subcapitulum (Figure 39).

Setation. Lanceolate, thick elevated medial longitudinal zone, with small dentitions, triangular in cross-section (Figures 3, 7): interlamellar (in) (Figures 4, 10); notogastral $c_{l}, c_{2}, d a, d m$, $d p$, la, lm, lp, $p_{1}, p_{2}, p_{3}, h_{l}, h_{2}, h_{3}$ (Figures 5, 6, 26); adanal (Figures 29, 31). Lanceolate, more or less flat, with elevated medial longitudinal zone: ro, le (Figures 4, 16, 25); simple: anal (Figure 27). Epimeral setae simple, with small barbs (Figure 18), but setae $4 a, 4 b$ particular in shape; $4 a$ is simple, elongate, thin, small barbs (Figure 33); $4 b$ simple, triangular, curving, small barbs (Figure 32); simple, sharply tipped: subcapitular setae; flabellate: genital; aggenital setae (Figures 30, 34).

Prodorsum. Polyhedral (in dorsal view) (Figures 1,2, 10); triangular to polyhedral in frontal view (Figure 38). Complex elevated interlamellar process (e.i.p): flat or slightly elevated (Figures 1, 2, 12, 13) forming two separate lateral processes, polyhedral in shape (Figures 38, 40). In lateral view each lateral process terminating in sharp tip, situated above le setal insertion (Figure 4 indicated by white asterisk in black square).

Two oblique parallel grooves on elevated zone of lateral process (Figures 1, 2, 4, 10, 12, 13, 38, 40 indicated by5); finger-shaped projection on anterior e.i.p, delineating a T-shaped, forward extending structure (Figures 2, 38, indicated by $i$ ); in setae curved (Figure 1,2,4), directing externally, inserted in front of e.i.p below lateral process (Figures 4, 12).

Bothidial zone with pusticulate cuticula (Figure 19). Bothridium (bo) cup-shaped with large, smooth, incomplete bothridial ring (bo.ri) (Figure 14); bothridial opening lateral, directing downward (Figures 12, 13); bothridial tooth (bo.to) clearly visible, rounded (Figure 14).

Sensillus ( $\mathrm{Si}$ ) filiform, barbate, arching to the top, tip usually pointed (Figures 1, 2, 12, 14); lamellar setae (le) inserted laterally on anterior part of lamellae (Figures 15,16) between lamellar tip and le setal insertion zone; conspicuous lamellar tip (la.ti) (Figure 16); curved rostral setae (ro) (Figures 12, 13, 21, 25), directing downwards; le setal insertion behind $r o$ insertion setal level (Figures 15, 16 ); large deep dorsosejugal suture (d.sj) (Figures 1, 2, $12,13)$.

Notogaster. Shape: anterior and posterior zone oval (in dorsal view) (Figures 1, 2, 10); convex in lateral view (Figures 9, 12,13); circumgastric furrow (s.c) present, easily discernible, situated antiaxially to $c_{1}, c_{2}, l a, l m, l p, h_{2}$ and paraxially to $h_{3}, p_{3}, p_{2}, p_{1}$ setal insertion level (Figures 1, 2, 10,13 indicated byl) (See Remarks). Fourteen pairs of setae $\left(c_{1}, c_{2}, d a, d m, d p, l a, l m, l p, h_{l}, h_{2}, h_{3}, p_{1}, p_{2}, p_{3}\right)$, all similar: lanceolate, thick, with elevated medial longitudinal zone, small dentitions, triangular in cross-section. However, $c_{2}$ setae differ slightly in shape and crosssection (Figures 6,7) from other notogastral setae (Figures 3, 5, da setae used as example); all setae (except $c_{2}$ ) extending backward; $c_{2}$ setae directing obliquely inwards (Figures 1, 2, 10, 12).

Humeral apophysis (h.ap) ovoid; anterior end barely overlapping posterior bothridial zone (Figures 9, 12, 13); h.ap with some transversal cuticular depressions (Figure 17 indicated by ${ }_{i}$ ), resulting in an undulate aspect to h.ap. Lyrifissures hardly discernible, only rounded $i m$ is observed (Figure 20).

Lateral region. Prodorsum: in setae clearly visible, situated in front of flat e.i.p (Figures 4, 12, 13); l.l.f well visible (Figure 16). Lamellae resembling elevated ribbon; Tutorium $(T u)$ strongly curving cuticular thickening (Figure 13); supratutorial depression (s.tu.d) deep (Figure 9, 13, 15); small anterior supratutorial depression (a.tu.d) (Figures 9, 21). Large deep posterior tutorial depression (p.tu.d) situated posteriorly on $T u$ basal zone (Figure 9, 13, 21). Pedotectum I $(P d I)$ prominent extending lamina, anteriorly rounded; large ovoid depression (dep) on posterior zone near Pedotectum II ( $P d I I)$; small, ovoid lamina directing downward (Figures 9, 13, 22). Discidium (dis) hardly discernible (See Ventral region).

Several depressions (dep) clearly visible basally to $P d I$ and above and behind acetabulum IV (Figure 9, 13, 21, 41). Anal plate terminating in long sharp tip (Figure 23), more clearly visible in lateral than ventral view.

Ventral region. Epimeres well delimited; 1 and 2 defined by deep furrows; bo.1, bo.2, bo.sj, 3 and 4 not noticeably separated; apo.1, apo.2, apo.sj and apo. 3 clearly visible (Figures 11,35). 
Epimeral chaetotaxy 3-1-3-3; setae 1a, 2a, 3a short. Epimeral setae $4 b$ (Figure 10, 32, 35), and 4a (Figure 33) differ in shape. Epimeral zone with medially deep polyhedral depression (Figures 11, 35 indicated by s). Discidium (dis) easily observed (Figure 35), triangular sharp tip. Genital plate slightly smaller than anal plate (Figure 35). Genital plate situated on elevated zone, externally surrounded by shallow depression (dep) (Figure 35). This furrow is connected to the anterior genital furrow (a.g.f) (Figures 11, 35, trajectory indicated by 1).

Genital plate with neotrichy: 6 to 11 pairs of setae (Figures 11,35,37) with symmetric or asymmetric distribution (See Remarks). Setae generally flabellate (Figure 34), some with very irregular shapes (Figure 37); in other cases setae absent, only insertions present (large insertions) (Figure 37).

Aggenital (ag) setae far from posterior border of genital opening, but situated posterolaterally on the surrounding genital furrow (Figures 11,35).

Anal plate terminating in long sharp tip (Figure 23, and 36 indicated byY). Large deep furrow observed surrounding anal plate anteriorly and medially, not completely surrounding the rear; in one instance the anal plate was deformed on one side.

Three pairs of adanal setae: $a d_{3}$ and $a d_{2}$ situated in lateral furrow of anal plate; $a d_{1}$ situated posteriorly on anal plate, outside lateral furrow (Figures 10, 35); rounded to polyhedral dep (Figures 11, 35) situated externally to genital and anal openings.

Legs. Setal formulae I (1-4-3-4-17-1) (1-2-2); II (1-3-3-3-15-1) (1-1-2); III (2-2-1-2-14-1) (1-1-0); IV (1-2-22-12) (0-1-0).

Remarks. Large variations in size were observed in both populations (Zimbabwe and Kenya). Initially the authors associated this variation in size with differences between males and females, but no correlation between sex and size was observed; in both sexes there were small and large specimens; sexes could be distinguished only by dissection.

Setae $h_{1}$ were not included when indicating the trajectory of s.c, as their position is variable (Figures 1,2), in some cases aligned to $h_{2}$ setae (Figure 1) and in others near $p_{2}$ setae (Figure 2). Positions of setae $p_{1}, p_{2}, p_{3}$ also varied.

Small dentitions present on surfaces of notogastral setae differ in size and number. In lateral view differences between notogastral cuticular ornamentations are easily visible; these variations are common in populations from Zimbabwe (Figure 12) and Kenya (Figure 13), but more so in populations from Kenya.

Large variation in the number of setae due to genital neotrichy, with asymmetry being very common. Setae frequently number 6-8 on each side; in one specimen from Zimbabwe only 4 setae were observed on a side, while in specimens from Kenya, six are most common. The largest variation was found in specimens from Kenya, with eleven setae on a side of the genital plate.

Depressions are very numerous on the ventral plate, clearly visible in ventral view; in lateral view a longitudinal oblique depression can be seen (Figure 41 indicated by 5), usually concealed by femur IV.

\section{Congocepheus thailandae sp. nov.}

(Figures 42-67)

Etymology. The specific epithet "thailandae" derives from Thailand, country of origin of type material.

Material examined. Holotype. Female. "THAILAND N²86. NE Bangkok Khao Yai Nai Park .759-859 mt. 26/XI/-3/XII/85. Leg. LOBL"; material deposited in the Collection of the Natural History Museum of Geneva (NHMG), Switzerland; preserved in 70\% ethanol. Paratype. One adult female, same locality and date as Holotype; deposited in Collection of MHNG; preserved in $46 \%$ ethanol. Material studied with SEM: three specimens, not deposited.

Diagnosis. Prodorsum. Large, triangular, central zone depressed or flat; setae in large, curved, situated on elevated interlamellar process, directing externally; ro setae curved, directing anteriorly; lamelar setae inserted far from apical lamellar zone. Anterior zone of lamellae welded to lateral prodorsal zone, lacking lamellar tip. Sensillus uncinate. Bothridial ring smooth; low lamellar furrow present, only slightly developed. Cornea superior of naso, with semicircular groove in posterior zone.

Notogaster. Fingerlike projection large, extending forward. Fourteen pairs of setae: $c_{1}, c_{2}, d a, d m, d p, l a, l m, l p$, $h_{1}, h_{2}$, situated on promontories; $h_{3}, p_{1}, p_{2,} p_{3}$, situated marginally on notogaster, all setae directing backwards; setae $c_{1}, c_{2}$ parallel and located side by side; integument with rugous elevated ridges. 

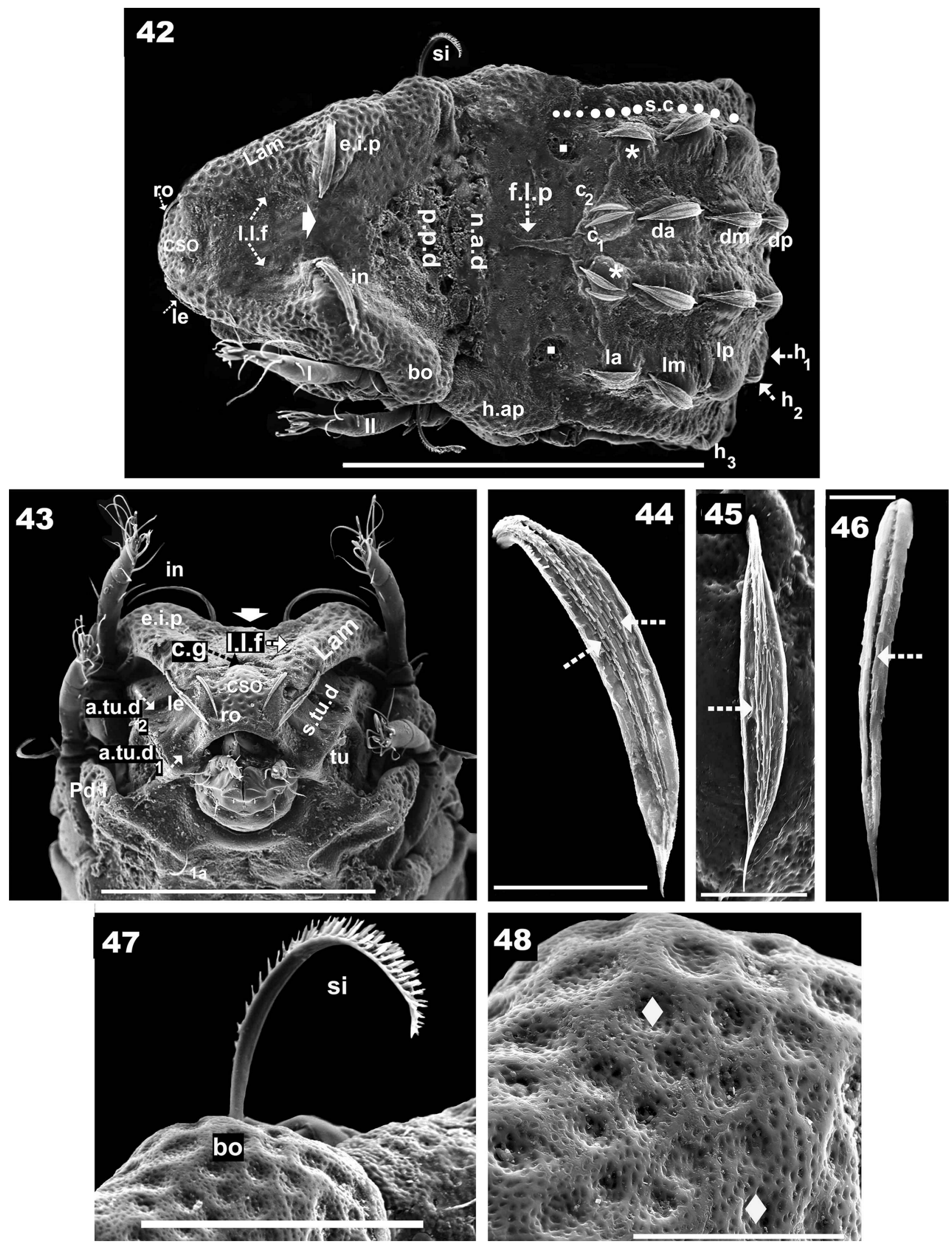

FIGURES 42-48. Congocepheus thailandae sp. nov. Adult female, SEM observations. 42. dorsal anteroposterior view; 43. frontal view; 44. prodorsal in seta; 45. notogastral $c_{1}$ seta; 46. prodorsal ro seta; 47. bothridium and sensillus; 48. cuticular ornamentation of bothridium. Scale bar: $\mathbf{4 2}=300 \mu \mathrm{m} ; \mathbf{4 3}=200 \mu \mathrm{m} ; \mathbf{4 4}=15 \mu \mathrm{m} ; \mathbf{4 5}=15 \mu \mathrm{m} ; \mathbf{4 6}=10 \mu \mathrm{m} ; \mathbf{4 7}=59 \mu \mathrm{m} ; \mathbf{4 8}=10 \mu \mathrm{m}$. 

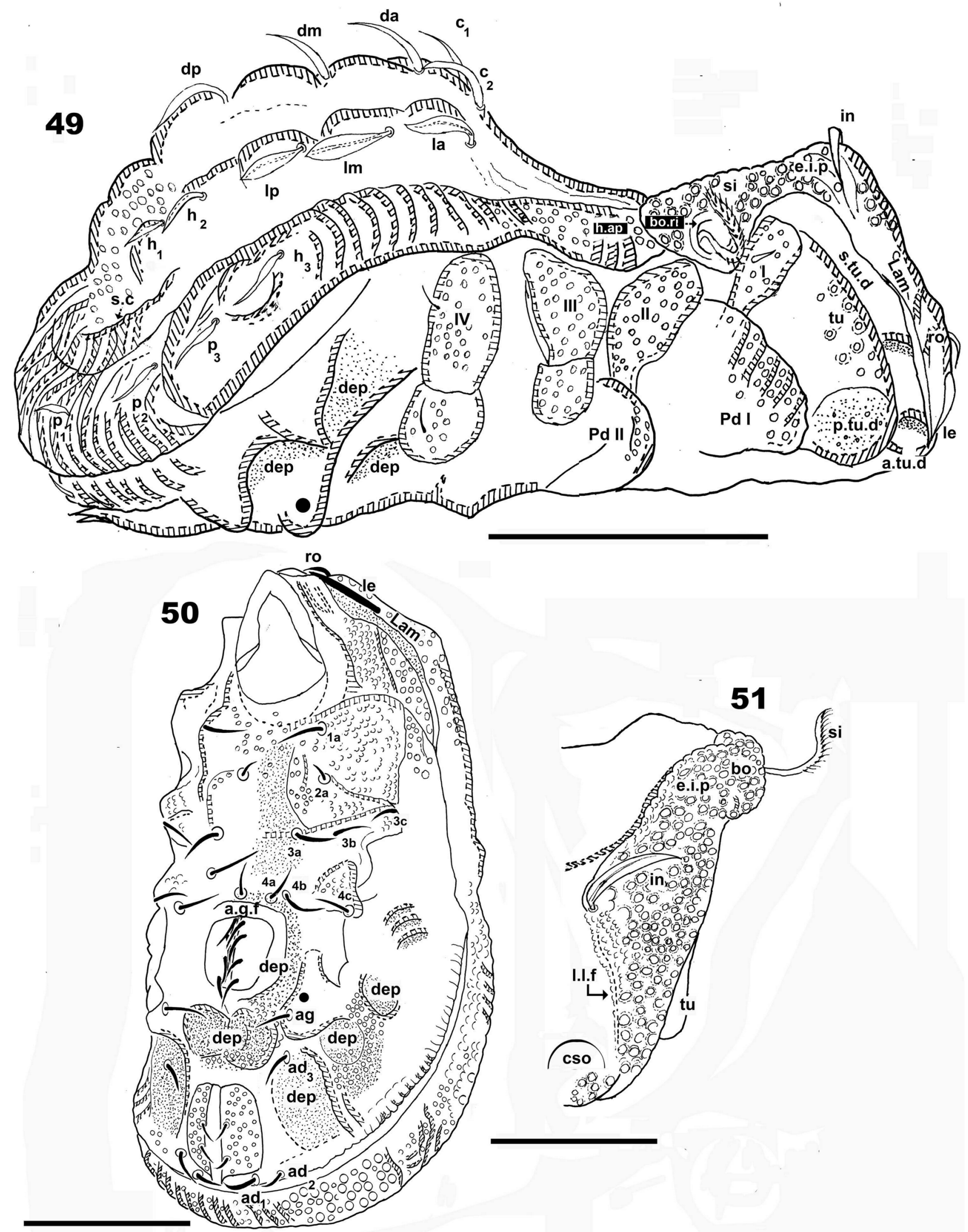

FIGURES 49-51. Congocepheus thailandae sp. nov. Adult female, Optical Microscopy. 49. lateral view; 50. ventral, inclined view; 51. frontal view. Scale bar: 49=160 $\mu \mathrm{m} ; \mathbf{5 0}=180 \mu \mathrm{m} ; \mathbf{5 1}=110 \mu \mathrm{m}$. 


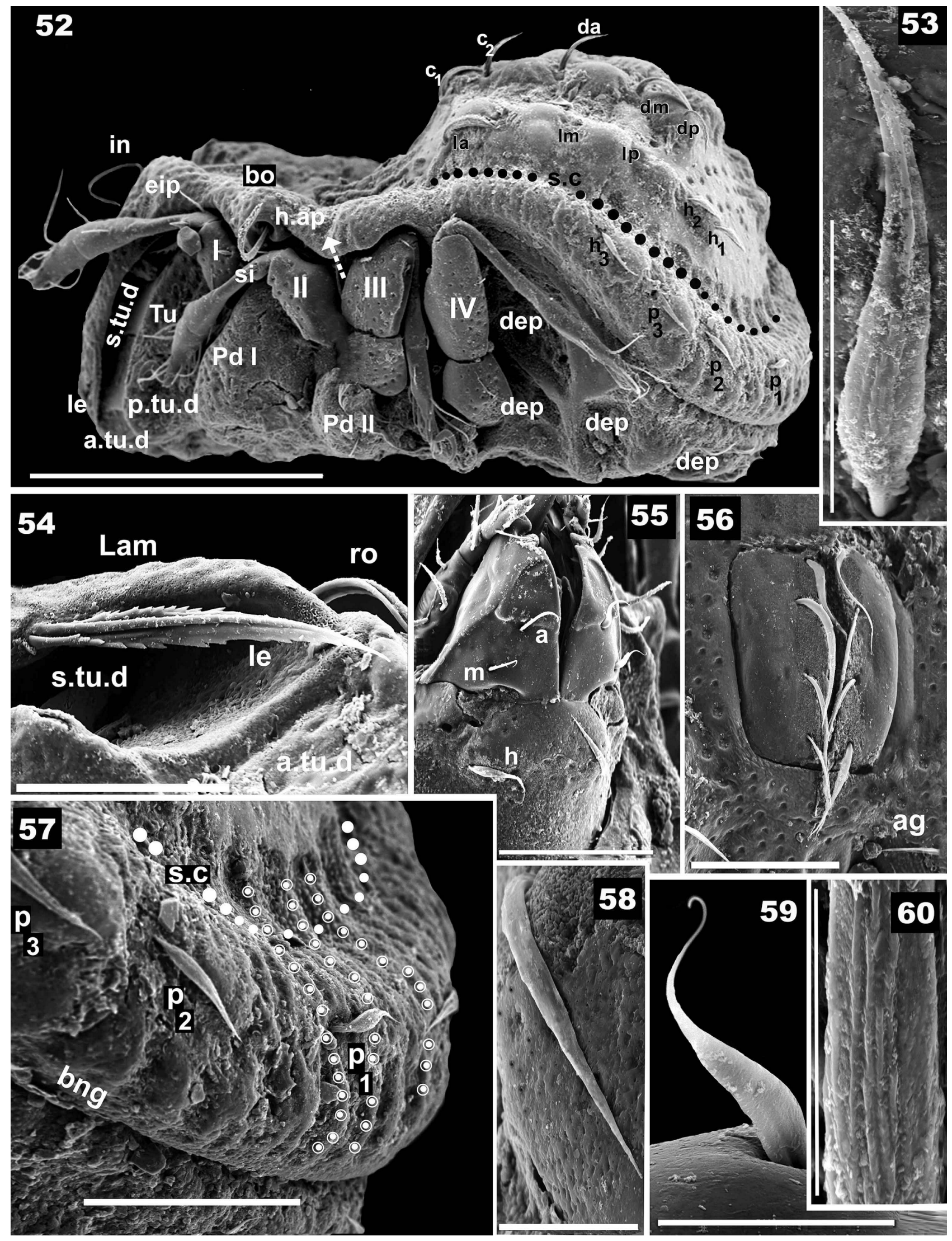

FIGURES 52-60. Congocepheus thailandae sp. nov. Adult female, SEM observations. 52. lateral view; 53. notogastral $p_{3}$ seta; 54. supratutorial depression and le seta; 55. subcapitulum; 56. genital plates; 57. notogaster posterolateral view; 58. subcapitular $h$ seta; 59. subcapitular $m$ seta; 60. ornamentation seta $p_{3}$. Scale bar: 52=200 $\mu \mathrm{m} ; \mathbf{5 3}=15 \mu \mathrm{m} ; \mathbf{5 4}=59 \mu \mathrm{m} ; \mathbf{5 5}=25$ $\mu \mathrm{m} ; \mathbf{5 6}=59 \mu \mathrm{m} ; \mathbf{5 7}=30 \mu \mathrm{m} ; \mathbf{5 8}=10 \mu \mathrm{m} ; \mathbf{5 9}=10 \mu \mathrm{m} ; \mathbf{6 0}=5 \mu \mathrm{m}$. 

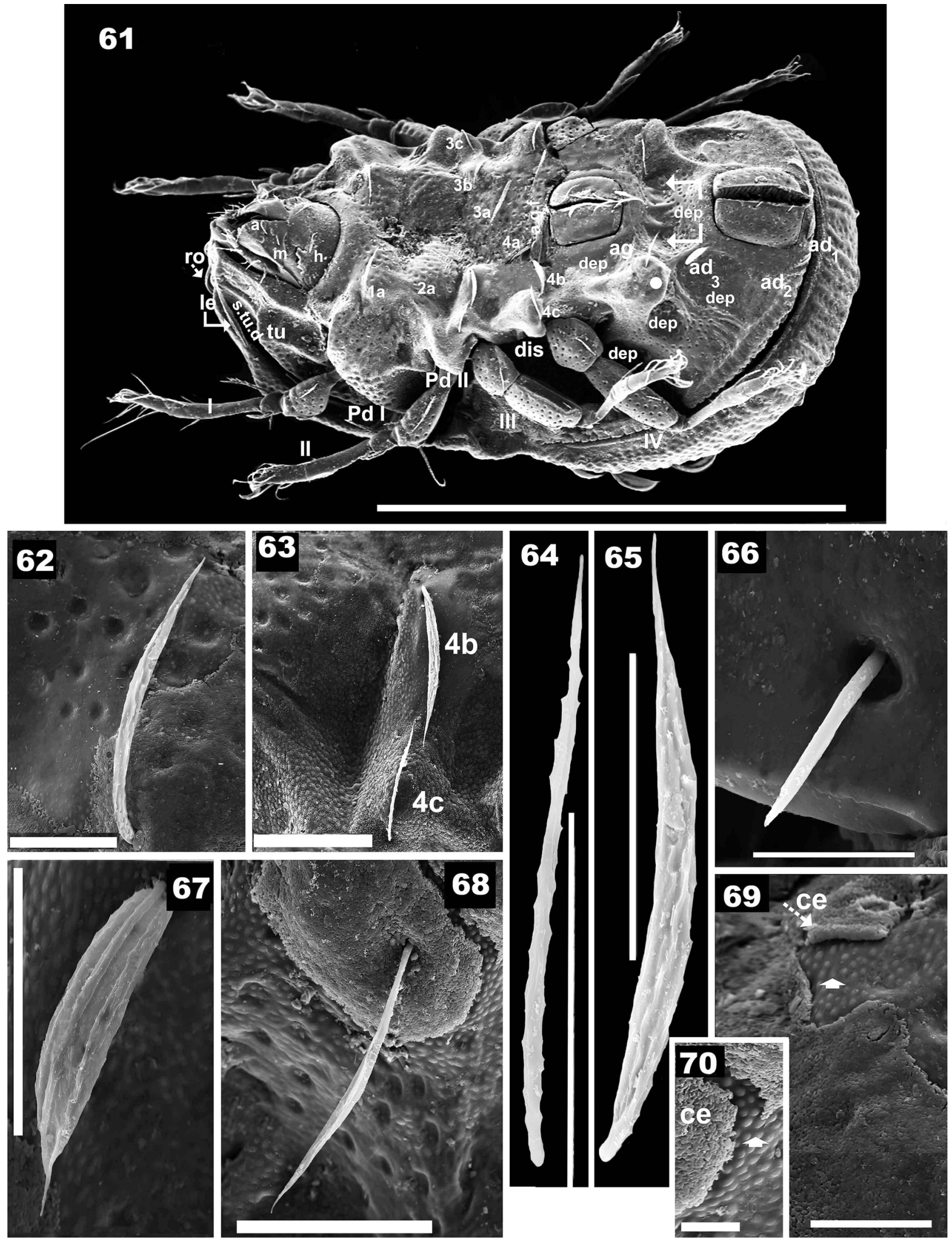

FIGURES 61-70. Congocepheus thailandae sp. nov. Adult female, SEM observations. 61. ventrally inclined view; 62. epimeral $l a$ seta; 63. epimeral seta $4 b, 4 c$; 64. epimeral $3 c$ seta; 65. epimeral $3 a$ seta; 66. anal seta; 67. adanal $a d_{3}$ seta; 68 . aggenital seta; 69. epimeral zone, cerotegument and cuticular ornamentation; 70. detail aggenital zone cerotegument and

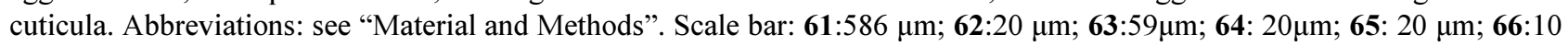

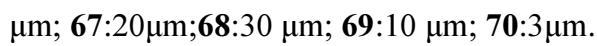


Ventral region. Epimeral, central zones depressed, marginal region elevated. Epimera 3-4 fused; epimeral chaetotaxy 1-1-3-3; four pairs of genital setae in a simple line; ag setae situated on rounded elevated structure.

Description. Measurements: SEM 556 (460-602) x 260 (242-273) (measurements on three specimens). Light microscopy: 580 (560-582) $\underline{x} 273$ (256-281).

Shape: Elongate oval (Figure 42).

Colour: Specimens without cerotegument, light brown to brown, observed in reflected light.

Cerotegument. Thin grainy layer (ce) (Figure 69, indicated by 5), mainly on posterior zone of notogaster (Figure 57) and epimeral zone (Figure 61), and around ag setal insertion (Figure 68); rest of body and legs absent; cerotegumental layer may have been affected by the long period in conservation liquid.

Integument. Foveate-foveolate (Figure 48, indicated byw): prodorsum: lamellar zone up to l.l.f (Figures 42, 43); anterior of prodorsum around CSO (Figure 43); bothridial and p.p.d zones (Figures 42, 47); notogaster: h.ap (Figure 42); $P d I, P d I I$ and $T u$ (Figures 43, 52).

Circular-ovoid fovea: notogastral zone: $n . a . d$ and both sides of f.l.p (Figure 42).Ventral region: subcapitular zone $h$ setae (Figure 58); epimeral zone (Figures 61,62,63); around genital opening (Figure 56); aggenital zone, but not very close to ag setae (Figure 68); lateral to ventral dep (Figure 61). Legs: femurs I, II and trochanter, femur III, IV (Figure 52).

Rugous with elevated ridges: lateral notogastral margin, zone of setae $p_{1}, p_{2}, p_{3}, h_{3}$, up to $h$.ap level (Figure 57 indicated by $\bullet$ ), in this zone, combined with circular-ovoid fovea; marginal ventral region; anal zone (Figure 61).

Pusticulate (Figures 69, 70 indicated by $i$ ): zone epimeral surrounding setae $4 c$ (Figure 63); zone near ag setae (Figure 68).

Setation. Lanceolate elongate with: smooth surface: $a g$ setae (Figure 68); medial ridge: notogastral $c_{1}, c_{2}, d a$, $d m, d p$, la, lm, lp (Figures 42, 45) ad setae (Figure 67); large basal, and thin anterior zone, medial ridge several lines: notogastral setae: $h_{3}, p_{3}, p_{2}, p_{1}$ (Figures 53, 57, 60); rugous surface: epimeral setae $1 a, 2 a, 3 a, 3 b, 4 a, 4 b$ (Figures 62, 63, 65); thin medial furrow: ro setae (Figure 46); two parallel lines with small barbs: in setae (Figure 44); barbate on both sides: le setae (Figure 54).

Filiform, irregular margin: epimeral setae, $3 c, 4 c$ (Figures 64). Simple: subcapitular $(a, m, h)$ (Figures 58, 59), ge (Figure 56), an (Figure 66).

Prodorsum. Triangular (dorsal view) (Figure 42); convex in lateral view (Figure 49); rostral margin rounded (Figures 43,51); e.i.p elevated (Figure 52), central depressed zone flat (Figures 42,43 indicated by $i$ ); large curving setae in, situated on e.i.p, directing externally (Figures 42, 43); ro setae clearly visible, curved, directing anteriorly, apical tips far from one another (Figure 43); le setae inserted laterally to lam, far from apical lamellar zone; setal insertion level more or less same level as ro setal insertion (Figures 43); anterior zone of lamellae welded to lateral prodorsal zone, lamellar tip absent (Figure 54).

Sensillus (si) uncinate (Figure 47). Bothridial ring (bo.ri) smooth, well defined, with bothridial tooth; l.l.f present, slightly developed (Figures 42, 43, 51), CSO present between ro setae (Figures 43, 51); poorly developed semicircular groove (c.g) in posterior zone (Figure 43).

Notogaster. Shape: in dorsal view anterior polyhedral and posterior oval (Figure 42); in lateral view convex (Figures 49, 52); d.sj narrow, slightly curving, well delimited; notogastral anterior depression (n.a.d) clearly visible (Figure 42).

Notogaster with promontories ( Figure 49); large, forward extending finger-like projection (f.l.p) in front of promontory zone (Figure 42). Lateral to f.l.p, at level of origin of lateral promontories, depressed semi-circular area (Figure 42 indicated by n). Fourteen pairs of setae: $c_{1}, c_{2}, d a, d m, d p, l a, l m, l p, h_{1}, h_{2}, h_{3}, p_{1}, p_{2,} p_{3}$. Four longitudinally aligned promontories separated by depressed zone (Figures 42,49 ); setae $c_{1}, c_{2}, d a, d m$, $d p$, situated on aligned central promontories; $l a, l m, l p, h_{1}, h_{2}$ situated on aligned lateral promontories (Figures 42, 49, 52); $h_{3}$, $p_{1}, p_{2,} p_{3}$, situated marginally notogastral zone (Figures 42, 49, 52, 57); all setae directing backwards; setae $c_{1}, c_{2}$ situated side by side, parallel (Figure 42); polyhedral h.ap large, easily observed (Figures 42, 49, 52); excavated Vshaped depression present, but angle of observation needs to be changed to permit clear view (Figure 52 indicated by 5 ).

Circumgastric depression (s.c) easily discernible (Figures 42, 52, 57 indicated by 1), originating slightly posterior to $h . a p$, with the following trajectory: lateral to $l a, l m, l p, h_{1}, h_{2}$, and internally to $h_{3}, p_{1}, p_{2,} p_{3}$ (Figures 42 , 52 ); in the posterior notogastral zone the trajectory is partially obscured by rugous elevated cuticular ridges (Figure 57). 
Lateral region. Dorsolaterally, lamellae clearly discernible, anterior zone welded to lateral notogastral zone, lamellar tip absent (Figure 54). Tu large lamina, curving margin (Figure 43, 49, 52). Deep s.tu.d running between and parallel to lamellae and $T u$; anteriorly a large pocket depression is observed (a.tu.d); followed by deep depression, p.tu.d (Figure 49, 52). Pd I, conspicuous extended lamina, rounded apex, particular microsculpture (See Integument). $P d$ II medium sized, ovoid lamina; dis hardly discernible (Figures 49, 52).

Bothridia cup-shaped; bothridial opening directing slightly downwards; smooth bo.ri incomplete, with bo.to clearly discernible (Figure 49).

Long, extending polyhedral humeral apophysis, rounded apex, basally undulated, anterior tip overlapping posterior bothridial part (Figures 49, 52). Series of large dep discernible behind leg IV (Figures 49, 52). Posterior notogastral zone (Figure 57 ) with clearly visible rugous elevated cuticular ridges.

Ventral region. Epimera: central zones depressed, marginal elevated zones (Figure 61). Epimera 3-4 fused, small; apo.1, apo.2, apo.sj and apo.3 well discernible (Figure 50).

Epimeral chaetotaxy 1-1-3-3 (See Remarks); dis clearly observed as triangular protuberance with rounded apex (Figure 61).

Genital plates small relative to anal plates; four pairs of genital setae in a simple line (Figure 50, 56); all setae more or less equal length (Figure 56); ag setae far from genital opening, situated laterally and posterior to genital opening, placed on elevated rounded structure (Figures 50,61 indicated by 1); elevated structure covered by cerotegumental layer. Three pairs of adanal setae; $a d_{3}$ situated far from $a g$ setae (Figure 50). Anal plate rectangular to polyhedral, small sharp tip (Figure 50); two pairs of anal setae. Lyrifissures not discernible. Ovoid paired depressions situated between anal and genital openings; ovoid-elongate depressions situated laterally to genital and anal openings (Figures 50, 61)

Legs. Setal formulae I( 1-3-2-3-16-1) (1-2-2); II( 1-4-3-3-15-1) (1-1-2); III( 2-3-1-2-14-1) (1-1-0); IV(1-2-2-313-1) (0-1-0). Large femoral groove (Femur III).

Remarks. Epimeral chaetoxy 1-1-3-3 was observed in five specimens studied. However, due to the lengthy preservation period, the authors are uncertain if the setae have degraded during this time. There is a possibility that they exist, especially as in some instances, vestiges of setal insertions were observed. Two noteworthy aspects are: a) the large variation in shape of notogastral setae, where setae $h_{3}, p_{1}, p_{2}, p_{3}$ are very different to the other notogastral setae; b) the different shapes of epimeral setae, where $3 b, 4 b$ are very different compared to $3 c$ and $4 c$.

\section{Complementary Description}

\section{Cavaecarabodes hauseri (Mahunka, 1989)}

Material examined. Vietnam "Lam Dong province Mt. Pehhatt near Quang Tryung Reservoir ca $8 \mathrm{Km}$ SW of Da. Lat $11^{\circ} 58^{\prime} 37.4 \mathrm{~N} 108^{\circ} 25^{\prime} 58.3 \mathrm{E} ; 1.590 \mathrm{~m}$ Evergreen hill forest .6. IX. 2003. Leg. P. SWEDINGEN"; 3 adult females, material deposited in the Collection of the Natural History Museum of Geneva (NHMG), Switzerland; preserved in $70 \%$ ethanol.

Description. Cerotegument. Granulate: principally found on notogaster and ventral region.

Integument. Circular-ovoid fovea (Figure 74, indicated by R): prodorsum: e.i.p; p.p.d (Figure 71); notogaster (Figure 71 indicated by R); epimeral zone; around genital and anal openings; on genital and anal plate; region of $a g$ and $a d$ setae; in ventral depressions ( $d e p)$.

Rugous with elevated ridges: lateral margin of notogaster zone of setae $p_{1}, p_{2}, p_{3}, h_{3}$, up to $h$.ap. level (Figure 71 indicated by z); marginal ventral region; laterally on anal zone. Reticulate-foveate: lamellar zone (Figure77 indicated by a); smooth: zone of CSO; near rostrum (Figure 77)

Setation. Filiform, elongate, serrate, with rib located medially: le setae (Figure 84, rib indicated by 1). Lanceolate, with three ribs: in, $n g$, ad setae (Figures 72, 73, 76, 83). Rugous ribs situated on either side of setal margin (Figures 72, 73 indicated byS), medial rib with small barbs (Figure 73 indicated by ${ }_{i}$ ). Lanceolate with two parallel medial ribs: ro setae (Figure 75, ribs indicated by i). Lanceolate elongate, smooth: ag setae (Figure 83). Simple, short, smooth surface: $a, m$, an setae (Figures 78, 79, 85); simple, short, surface with dentitions: $h$ (Figure 80); simple, long, smooth: ge setae (Figure 81); simple, long, barbate: epimeral setae (Figure 82). 


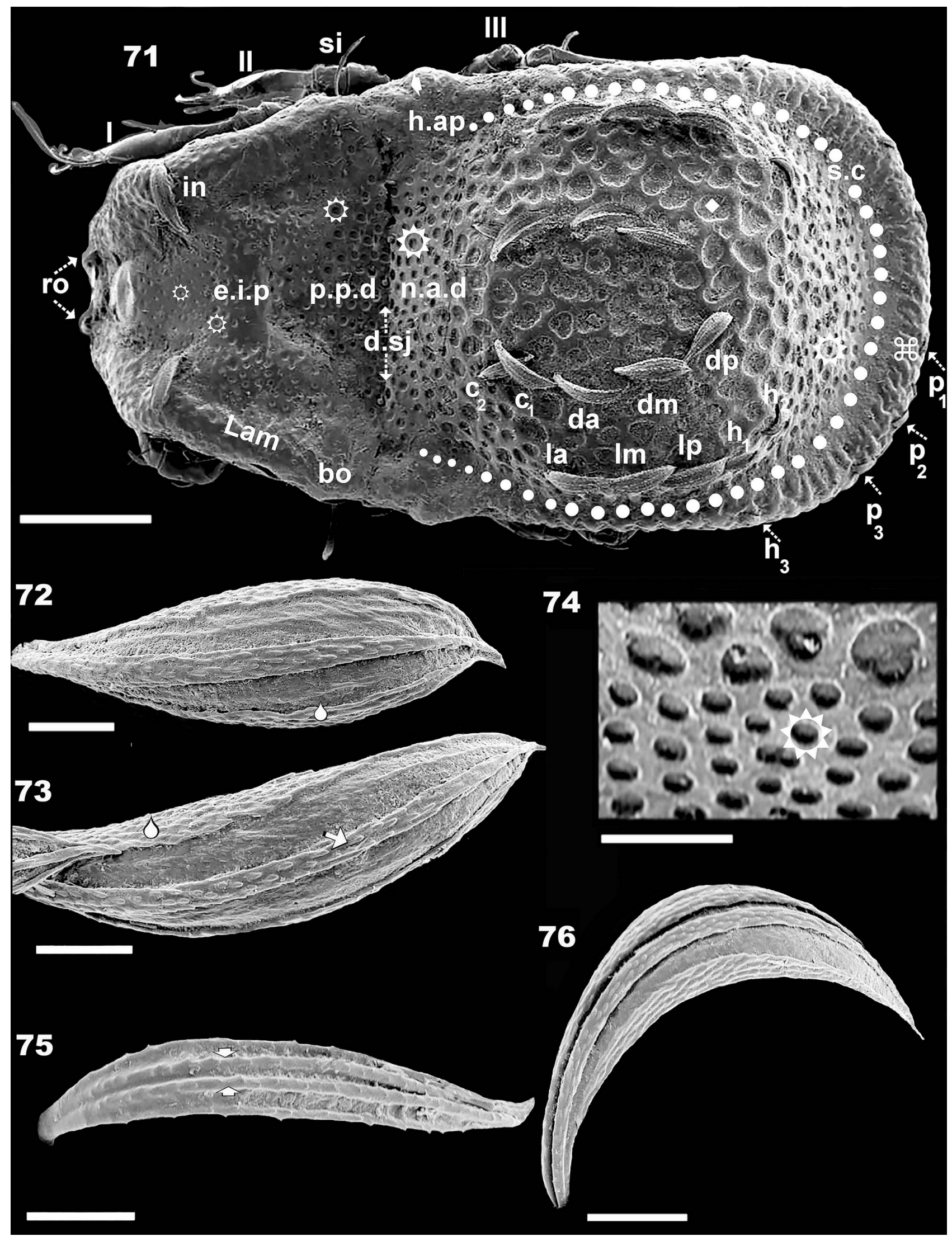

FIGURES 71-76. Cavaecarabodes hauseri (Mahunka, 1989) Adult female, SEM observations. 71. dorsal view; 72. notagastral seta, dorsal view; 73. notogastral seta, inclined view; 74. cuticular microsculpture; 75. rostral seta; 76. interlamellar seta. Scale bar: $\mathbf{7 1}=100 \mu \mathrm{m} ; \mathbf{7 2}=12 \mu \mathrm{m} ; \mathbf{7 3 1 2} \mu \mathrm{m} ; \mathbf{7 4}=15 \mu \mathrm{m} ; \mathbf{7 5}=10 \mu \mathrm{m} ; \mathbf{7 6}=20 \mu \mathrm{m}$. 

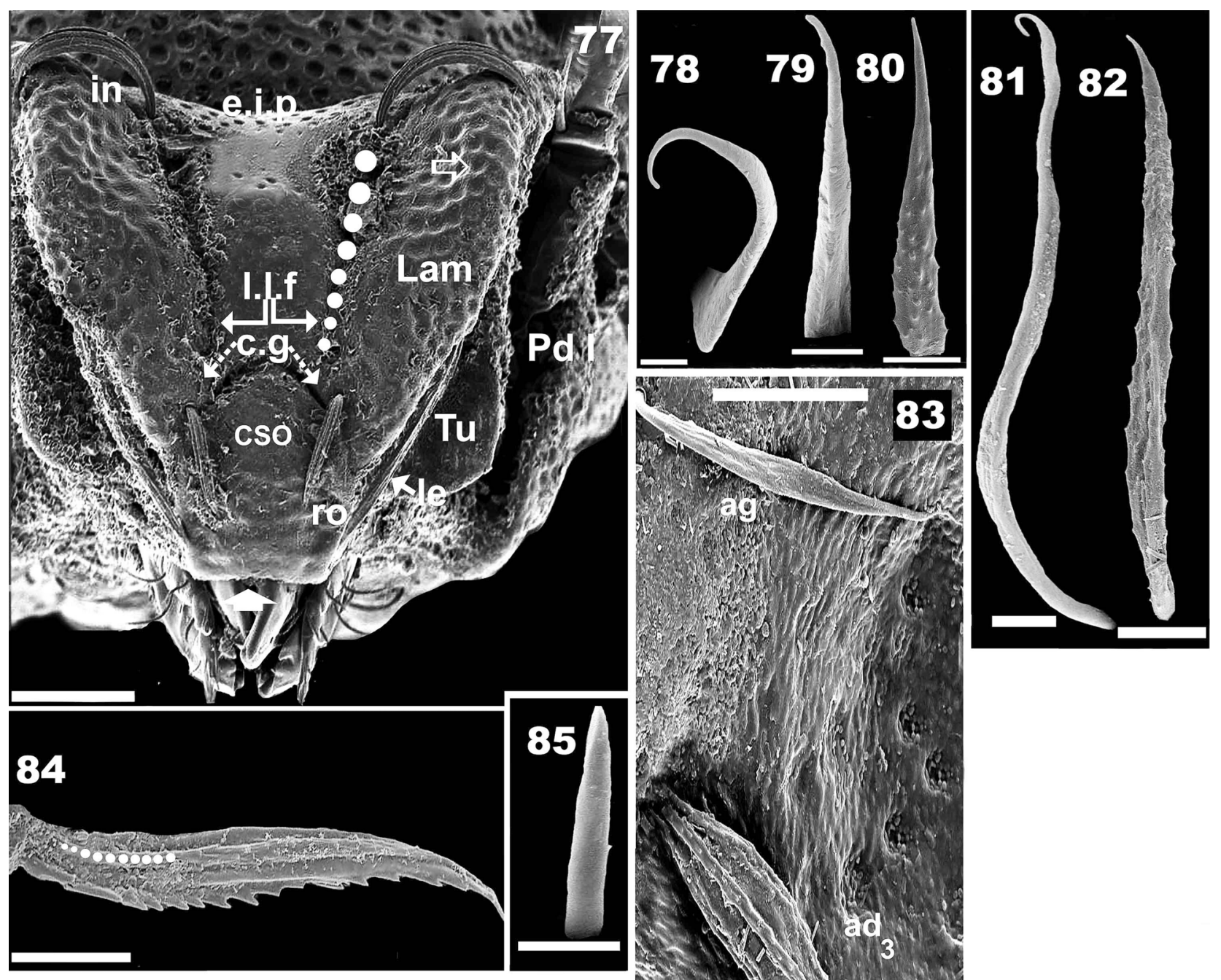

FIGURES 77-85. Cavaecarabodes hauseri (Mahunka, 1989) Adult female, SEM observations. 77. prodorsum frontal view; 78. subcapitular seta $a$; 79. subcapitular seta $m$; 80. subcapitular seta $h$; 81. genital seta; 82; epimeral seta $4 b$; 83. adanalaggenital zone; 84. lamelar seta; 85. anal seta. Scale bar: 77=59 $\mu \mathrm{m} ; \mathbf{7 8}=2 \mu \mathrm{m} ; \mathbf{7 9}=2 \mu \mathrm{m} ; \mathbf{8 0}=5 \mu \mathrm{m} ; \mathbf{8 1}=5 \mu \mathrm{m} ; \mathbf{8 2}=10 \mu \mathrm{m}$; $\mathbf{8 3}=10 \mu \mathrm{m} ; \mathbf{8 4}=20 \mu \mathrm{m} ; \mathbf{8 5}=5 \mu \mathrm{m}$.

Prodorsum. Rostral margin rectilinear (Figure 77, indicated by ¿). Lamellae dorsolateral, laterally well-defined (Figure 77); l.l.f clearly visible (Figure 77). CSO present (Figure 77) on anterior zone between ro setae, delimited posteriorly by a semicircular groove (c.g) (Figure 77, indicated by5); l.l.f extending from in setal level to c.g; le setae situated laterally, far from and posterior to $r o$ setal level; la.ti absent. $T u$ and $P d I$ clearly visible in frontal view (Figure 77).

Notogaster. Fourteen pairs of setae $\left(c_{1}, c_{2}, d a, d m\right.$, $d p$, la, $\left.l m, l p, h_{l}, h_{2}, h_{3}, p_{1}, p_{2}, p_{3}\right)$ similar shape (Figure 71$)$; all setae extending backward; $c_{1}$ and $c_{2}$ setae closely adjacent; insertion levels almost parallel; $c_{2}$ small relative to $c_{1}$. Circumgastric furrow clearly discernible externally to $l a, l m, l p, h_{l}, h_{2}$ setae (Figure 71 indicated by 1 ).

Remarks. By making use of SEM, the diagnosis (in Fernandez et al. 2013a) related to setae is improved. In that text:

"Setation: barbate, le; simple, subcapitular, an; lanceolate, in, notogastral, ro, genital, aggenital, epimeric and adanal" should be changed to: "Setation: filiform, elongate, serrate, with rib located medially: le setae; lanceolate, with three ribs: in, $n g, a d$ setae; lanceolate with two parallel medial ribs: ro setae; lanceolate, elongate, smooth: ag setae; simple, short, smooth surface: $a, m$, an setae; simple, short, surface with dentitions: $h$; simple, long, smooth: ge setae; simple, long, barbate: epimeral setae. The other diagnostic aspects are correct as indicated. 
Also worth noting are the particularities found on the integument, described in Fernandez et al. 2013a, but complemented by this study.

\section{Discussion}

At present, two species of the genus Synkrotima are known: Synkrotima zimbabwae Fernandez, Theron, Leiva, Tiedt 2017, and S. tsalakpmenoi sp. nov. These two species are easily recognizable by several characteristics, but three of these should be enough to differentiate them 1) notogastral cuticular microsculpture: foveate in $S$. zimbabwae while in $S$. tsalakpmenoi sp. nov. longitudinally aligned cuticular chords form rugose integument; 2) notogastral setae in $S$. zimbabwae are lanceolate with one longitudinal rib, and in $S$. tsalakpmenoi sp. nov. notogastral setae are lanceolate with thick elevated medial longitudinal zone and small dentitions, appearing triangular in cross-section; 3) genital setation: normal chaetotaxy (4 pairs) in S. zimbabwae, in S. tsalakpmenoi $\mathbf{s p .}$ nov. between six and eleven pairs (neotrichy).

With regard to this genus in Kenya, the following interesting aspects should be noted. Large numbers of specimens were collected from different regions of this country, and although we studied those with a homogenous population, specimens from other areas are nonhomogeneous or mixed populations, vastly complicating recognition and identification of further species.

All known species of the genus Congocepheus were studied by the authors in previous papers (Fernandez et al. 2013a; Fernandez et al. 2013b; 2014; Fernandez et al. 2016a, 2016b; Fernandez et al. 2017a; Fernandez et al. 2017b). C. orientalis and C. thailandae sp. nov. are closely related and present a series of common characteristics, such as: triangular prodorsum; flat, depressed central zone; fourteen pairs of setae; setae $c_{1}, c_{2}, d a, d m, d p, l a, l m$, $l p, h_{1}, h_{2}$ situated on promontories; $c_{l}, c_{2}$ setae situated adjacent to each other; the presence of a finger like projection, amongst others. A number of distinguishing particularities that facilitate their identification is given in table 1.

TABLE 1. Comparison of diverging morphological characters between C. orientalis and C. thailandae sp. nov.

\begin{tabular}{lll}
\hline & C. orientalis & C. thailandae sp. nov. \\
\hline finger like projection & Small & large \\
in setae & Lanceolate, faintly dentate & Lanceolate elongate, two parallel lines with small barbs \\
Ng setae: $c_{1}, c_{2}, d a, d m, d p, l a, l m, l p$ & Lanceolate, faintly dentate & Lanceolate elongate, medial ridge: \\
ng setae: $h_{3}, p_{3}, p_{2}, p_{1}$ & Lanceolate, faintly dentate & Lanceolate elongate,with large basal, and thin anterior \\
& & zone, medial ridge several lines \\
Aggenital setae & Lanceolate, faintly dentate & Lanceolate elongate, with: smooth surface: \\
Epimeral setae & Lanceolate, faintly dentate & Lanceolate elongate rugous surface \\
Dep between genital and anal opening & Not visible & Round paired \\
\hline
\end{tabular}

The genus Cavaecarabodes was established 2014, with type species Cavaecarabodes pulchritude Fernandez, Theron, Rollard, Rodrigo Castillo, 2014. The species Congocepheus hauseri Mahunka, 1989 was included in this new genus. Type material of Co. hauseri was redescribed in 2013a, making use of optical micoscopy.

This complementary study using SEM permits confirmation of some structural aspects of the prodorsum and notogaster, which could not be observed in detail on the type material due to its state of conservation. Likewise, we were able to obtain more precise information on: a) integumental microsculpture, principally the characteristis of circular-ovoid fovea (only given in original redescription by a schematic drawing) and the reticulate-foveate zone; b) the presence of a medially located rib on le setae; the presence of three ribs on setae in, $n g$, and ad setae; two parallel ribs on ro setae; simple long barbate epimeral setae. 


\section{Acknowledgements}

This work is based on research supported in part by the National Research Foundation of South Africa (UID) 85288. Any opinion, findings and conclusions or recommendations expressed in the manuscript are those of the authors and therefore the NRF does not accept any liability in regard thereto.

\section{References}

Evans, G.O. (1992) Principles of acarology. C.A.B International, Cambridge. Wallingford (UK). 563 pp.

Fernandez, N., Theron, P. \& Rollard, C. (2013a) The Family Carabodidae V. The genus Congocepheus (First part), with redescriptions of Congocepheus heterotrichus Balogh, 1958, Congocepheus orientalis Mahunka, 1987 and Congocepheus hauseri Mahunka, 1989. International Journal of Acarology, 39 (8), 600-614. http://dx.doi.org/10.1080/01647960.2013.858747

Fernandez, N., Theron, P., Rollard, C. \& Tiedt, L. (2013b) The family Carabodidae (Acari: Oribatida) V. The genus Congocepheus (second part), with a redescription of Congocepheus involutus Mahunka, 1997, and descriptions of Congocepheus gabonensis and Congocepheus extactastesi sp. nov. Zoosystema, 35 (4), 587-609. http://dx.doi.org/10.5858/z2013n4a8

Fernandez, N., Theron, P., Rollard, C. \& Rodrigo Castillo, E. (2014) Revision of the family Carabodidae (Acari: Oribatida) V (third part). Redefinition of Congocepheus, definition of Cavaecarabodes gen. nov. and descriptions of three new species, Congocepheus germanicus sp. nov., Cavaecarabodes pulchritude gen. nov., sp. nov., and Cavaecarabodes anouchkae gen. nov., sp. nov. International Journal of Acarology, 40 (7), 595-585. http://dx.doi.org/10.1080/01647960.2014.959059

Fernandez, N., Theron, P. \& Leiva, S. (2016) Revision of the family Carabodidae (Acari, Oribatida) V. Fourth part. Two new species of the genus Congocepheus from the Republic of Rwanda: Congocepheus rwandensis sp. n., and Congocepheus kayoveae sp. n. Zookeys, 586, 19-41. https://doi.org/10.3897/zookeys.556.7011

Fernandez, N., Theron, P. \& Leiva, S. (2016) Revision of the family Carabodidae (Acari: Oribatida) XI. Congocepheus kardiae sp. nov. and Zimbabweae pluosiae gen. nov., sp. nov. from the Republic of Zimbabwe. International Journal of Acarology, 42 (7), 341-357. http://dx.doi.org/10.1080/01647954.2016.1199138

Fernandez, N., Theron, P. \& Leiva, S. (2017) Revision of the family Carabodidae (Acari: Oribatida) V (Fifth part). Redescription of Congocepheus latilamellatus Mahunka 1984, with complementary studies of C. ornatus, Mahunka 1983. Descriptions of Tanzaniacepheus gen. nov. and Zimbabwecepheus gen. nov. Zootaxa, 4324 (2), 315-330. https://doi.org/10.11646/zootaxa.4324.2.5

Fernandez, N., Theron, P., Leiva, S. \& Tiedt, L. (2017) Revision of the family Carabodidae (Acari: Oribatida) XIII. Congocepheus camerunensis sp. nov. and Synkrotima zimbabwae gen. nov., sp. nov. from the Republic of Zimbabwe. Systematic \& Applied Acarology, 22 (11), 1822-1842. http://dx.doi.org/10.11158/saa.22.11.4

Grandjean, F. (1958) Observation et conservation des très petits Arthropodes. Bulletin de Muséum d'Histoire Naturelles, Paris, 21 (2), 363-346.

Krantz, G. \& Walter, D. (2009) A manual of acarology. 3rd ed. Texas Tech University Press. Lubbock (TX). 807 pp.

Mahunka, S. (1987) Neue und interessante Milben aus dem Genfer Museum LX. Oribatids from Sabah (East Malaysia) II. (Acari: Oribatida). Revue suisse de Zoologie, 94, 765-817.

Mahunka, S. (1989) New and interesting mites from the Geneva Museum LXV. Oribatids of Sumatra (Indonesia) I (Acari: Oribatida). Revue suisse de Zoologie, 96, 433-459.

Norton, R. \& Behan-Pelletier, V. (2009) Suborder Oribatida. In: Krantz GW, Walter DE (eds.) A manual of acarology. 3rd ed. Texas Tech University Press. Lubbock (TX). p. 430-594.

Travé, J. \& Vachon, M. (1975) François Grandjean 1882-1975 (Notice biographique et bibliographique). Acarologia, 17 (1), 119. 